\title{
sciendo
}

10.2478/AMB-2019-0006

\section{ASSESSMENT OF CHAENOMELES MAULEI FRUIT JUICE EFFECTS IN TESTS FOR DEPRESSION AND ANXIETY}

\author{
V. Borisova, M. Eftimov, S. Valcheva-Kuzmanova \\ Department of Pharmacology and Clinical Pharmacology and Therapeutics, Faculty of Medicine, \\ Medical University "Prof. Dr. Paraskev Stoyanov" - Varna, Bulgaria
}

\begin{abstract}
Depression and anxiety are prevalent chronic psychiatric disorders affecting many people worldwide. Over the past decades, much attention has been drawn to herbal psychopharmacology, offering fewer adverse reactions. The main bioactive compounds in Chaenomeles maulei fruits are polyphenols known for their behavioral effects. The objective of the present study was to assess Chaenomeles maulei fruit juice (CMFJ) effects in tests for anxiety and depression. The animals used were 32 male healthy Wistar rats treated orally with CMFJ for 16 days. They were divided in four groups of 8 animals. The control group received distilled water and the rest of the groups were treated with CMFJ at 2.5, 5 and $10 \mathrm{ml} / \mathrm{kg}$ doses. We assessed the social interaction time as a measure of anxiety and the immobility time in the forced swim test as a measure of behavioral despair. In the social interaction test, the 14 days administration of CMFJ did not produce any significant changes in the time spent in social interaction. After 16 days of administration all doses of CMFJ significantly decreased the immobility time of the rats $(p<0.05)$ in comparison to the control group. These results allow making the conclusion that CMFJ lacked anxiolytic activity, but showed an antidepressant-like effect.
\end{abstract}

Key words: anxiety, depression, forced swim test, Chaenomeles maulei, polyphenols

Corresponding author: Vesela Borisova, Department of Pharmacology and Clinical Pharmacology and Therapeutics, Faculty of Medicine, Medical University Prof. Dr. Paraskev Stoyanov, 55, Marin Drinov Street, 9000 Varna, Bulgaria, e-mail: vessela90@abv.bg

\section{INTRODUCTION}

$\mathrm{D}$ epression is a chronic psychiatric disorder manifesting with lowered pleasure, mood and interest. It is a common and recurring disease, affecting negatively a person's lifestyle. Depression is considered one of the main reasons of disability worldwide and is highly resistant to treatment [1]. Anxiety is a common symptom of many psychiatric disorders as well as other medical conditions [2]. Worldwide, one in five people at least once in their lives have met with clinical criteria of anxiety disorder [3]. By the year
2030, depression is predicted to account for the second greatest increase in morbidity after cardiovascular diseases. Depression can be diagnosed as "major depression" which comprises numerous symptoms including anxiety. Important mechanisms in the pathogenesis of depression are impairment of the monoamine transporters, decrease in their production or secondary messenger systems dysfunction. Recently, some attention has been drawn to the role of hypothalamus-pituitary-adrenal dysfunctions, changes in glutamatergic transmission, impaired opioid function and abnormal circadian rhythm $[4,5]$. 
Although there are many highly effective antidepressants available, there is an increasing interest in natural antidepressants with fewer side effects. Most of the phytodrugs are "over-the-counter" products with a complex mechanism of action, involving a multitude of biological responses. In the majority of cases, the medicinal plants with antidepressant action affect the reuptake mechanism and receptor binding of monoamines, in addition to some endocrine, antioxidant, neuro-immunological modulation [6]. Some herbal drugs with antidepressant activity, which have undergone preclinical trials, contain mainly polyphenols and triterpenes as components exerting pharmacological effects [7].

Chaenomeles is a genus of shrubs from the Rosaceae family. Native to Japan, Korea, China, Bhutan and Burma, the plants are related to the quince (Cydonia oblonga) and the Chinese quince (Pseudocydonia sinensis). The plants are widely applied in the traditional medicine of those countries due to their diverse effects. An investigation, aiming to elucidate the main bioactive principles of Chaenomeles species, showed that polyphenols, especially flavan-3-ols, were highly abundant. It has been observed that the antioxidant activity of the Chaenomeles fruits correlated to their total polyphenol contents [8]. Chaenomeles maulei has recently been introduced to the Bulgarian market in the form of a bio juice. The main bioactive compounds in Chaenomeles maulei fruits are polyphenols, such as flavonoids and phenolic acids, but also high amounts of vitamin $\mathrm{C}$ [9].

Polyphenols have been investigated and proven protective against a wide range of diseases including psychiatric disorders. Some of them cross the blood-brain barrier in concentrations high enough to exert an effect. Their brain penetration depends on their lipophilicity, interactions with transport proteins, like P-glycoprotein and stereochemistry [10]. Animal studies have demonstrated that polyphenols cross the blood-brain barrier independently of their route of administration [11]. Polyphenols have been shown to induce behavioral effects such as improved working memory, mood and attention [12]. The neuroprotective effects of CMFJ have not been studied yet.

Ginkgo biloba extract, which is rich in flavonoids, improved brain activity, short-term memory, learning and concentration in animals suffering from cognitive impairment [13]. Aronia melanocarpa fruit juice, containing polyphenols as bioactive components, dose-dependently decreased the immobility time in the forced swim test [14]. This suggested an antidepressant-like effect. Some of the mechanisms, related to the positive effects of polyphenols on mood and cognition, include a reduction in the levels of free radicals [15], increase in cerebral blood flow, interaction with receptors, ion channels and growth hormones, increase in the levels of norepinephrine, dopamine and 5-TH in prefrontal cortex, hypothalamus and striatum [16].

The neurobehavioral properties of polyphenols are well-studied, but the biological activity of CMFJ has not been examined yet.

\section{AIM OF THE STUDY}

The aim of the present study was to investigate the effect of Chaenomeles maulei fruit juice on rats' behavior in the forced swim test and social interaction test.

\section{MATERIAL AND METHODS}

\section{Animals}

The experimental animals were healthy male Wistar rats with a mean weight of $250 \pm 30 \mathrm{~g}$. During the experiment, the animals were housed in plastic cages in a well ventilated room maintained at $22 \pm 1^{\circ} \mathrm{C}$ and on a $12 / 12$ light/dark cycle. They had free access to food and drinking water.

All procedures concerning animal treatment and experimentation were conducted in conformity with the national and international laws and policies (EU Directive 2010/63/EU for animal experiments) and were approved by Bulgarian Food Safety Agency (Document 141/23.06.2016).

\section{Chaenomeles maulei fruit juice (CMFJ)}

Fruits from Chaenomeles maulei were grown in the Balkan Mountains, Bulgaria, in the region of Troyan. After handpicking, fresh fruits were grinded, crushed and squeezed. The juice was filtered, preserved with potassium sorbate $(1.0 \mathrm{~g} / \mathrm{l})$ and stored at $0{ }^{\circ} \mathrm{C}$ till the experiments. The total content of phenolic compounds was determined by the spectrophotometric Folin-Ciocalteu assay [17]. Absorbance was read at $760 \mathrm{~nm}$. Gallic acid was used as a standard. The total content of phenolic compounds was $8900.00 \mathrm{mg}$ gallic acid equivalents per liter of juice.

\section{Experimental procedure}

The experiments were carried out on 32 male healthy Wistar rats. They were divided in 4 groups of 8 animals each and were treated orally through an orogastric cannula. The animals were allocated in the following groups: Control, $\mathrm{CMFJ}_{2.5}, \mathrm{CMFJ}_{5}$ and $\mathrm{CMFJ}_{10}$. The Control group was treated with distilled water $(10 \mathrm{ml} /$ $\mathrm{kg}$ ). The rest of the groups received CMFJ at doses of $2.5,5$ and $10 \mathrm{ml} / \mathrm{kg}$ once a day. The doses of 2.5 and 5 $\mathrm{ml} / \mathrm{kg}$ were diluted with distilled water to a total volume of $10 \mathrm{ml} / \mathrm{kg}$. The doses were chosen on the basis of 
previous experiments which showed that Aronia melanocarpa fruit juice at these doses produced relevant central nervous system effects in rats $[14,18]$. The administration of the juice lasted for 16 days.

\section{Social interaction test}

The social interaction test is a well-known test to study the state of anxiety [19]. In this test, the dependent variable is the time spent in social interaction between partners. Each rat was tested for social interaction with an unknown test partner that did not differ by more than $10 \mathrm{~g}$ in weight. Both members of a pair had the same drug treatment. The square arena $(100 \times 100$ $\times 40 \mathrm{~cm}$ ) of the open field apparatus was used as a test box. The rats were gently placed at the opposite corners of the arena. The following behaviors were observed and scored during a 5 min session: sniffing, nipping, grooming, following, mounting, kicking, jumping on and crawling under or over the partner. The passive contact (sitting or lying with bodies in contact) was not included in the social interaction score [19]. A decrease in social interaction, without a concomitant decrease in locomotor activity, is defined as a specific anxiogenic effect; an increase in social interaction, without an increase in locomotor activity, is defined as a specific anxiolytic effect [20]. The test was performed on the $14^{\text {th }}$ day, 60 min after CMFJ administration.

\section{Forced swim test}

We assessed the immobility time of rats as a measure of behavioral despair in the forced swim test [21]. It is considered an adequate test for screening of antidepressants. It produces a mental condition of hopelessness, reflecting the human depressed state, in which the immobility is a direct reaction to the test itself and does not persist outside the test situation. The animals are tested one by one in a transparent plexiglas cylinder $(17 \mathrm{~cm}$ in diameter and $60 \mathrm{~cm}$ in height) containing water $(22 \pm 1$ $\left.{ }^{\circ} \mathrm{C}\right)$. The cylinders were filled so that there was left space at the top, not allowing the animals to escape. The test was performed in two sessions (training and test) separated by 24 hours. In the training session, on the $15^{\text {th }}$ experimental day, one hour after CMFJ treatment, an animal was dropped down in water and its activity was documented for $5 \mathrm{~min}$. The test session was conducted on the $16^{\text {th }}$ day, 60 min after the CMFJ administration and immobility time was recorded. It was the time spent floating passively or just making those movements necessary to maintain the animal's head above water [22].

\section{Statistical analysis}

Results are presented as mean \pm S.E.M. The data were tested by one-way ANOVA, followed by a Dunnett's Multiple Comparison Post Test. GraphPad Prism statistical software was used to perform all analyses. A level of $p<0.05$ was considered significant.

\section{RESULTS}

\section{Social interaction test (SIT)}

In the SIT, the time spent in social contacts between the partners was not significantly affected after 14 days of CMFJ administration. The social interaction time of the $\mathrm{CMFJ}_{2.5}$ group was slightly decreased compared to the Control group and elevated in $\mathrm{CMFJ}_{5}$ and $\mathrm{CMFJ}_{10}$ groups (Table 1). The analysis of the results showed a dose-dependent trend towards increasing the interaction time (Fig. 1).

Table 1. Effect of CMFJ on the time spent in social interaction in the social interaction test (SIT) and the immobility time in the forced swim test (FST) in rats; ${ }^{*} p<0,05$ vs. Control

\begin{tabular}{|c|c|c|c|c|}
\hline Test Group & Control group & $\mathrm{CMFJ}_{2.5}$ & $\mathrm{CMFJ}_{5}$ & $\mathrm{CMFJ}_{10}$ \\
\hline $\begin{array}{l}\text { Time spent in } \\
\text { social interaction } \\
\text { in the SIT (sec) }\end{array}$ & $17.89 \pm 2.3$ & $15.71 \pm 1.31$ & $17.58 \pm 2.75$ & $18.66 \pm 3.19$ \\
\hline $\begin{array}{l}\text { Immobility time } \\
\text { in the FST (sec) }\end{array}$ & $66.38 \pm 8.43$ & $41.00 \pm 5.17^{*}$ & $37.88 \pm 8.34^{*}$ & $39.5 \pm 5.61^{*}$ \\
\hline
\end{tabular}

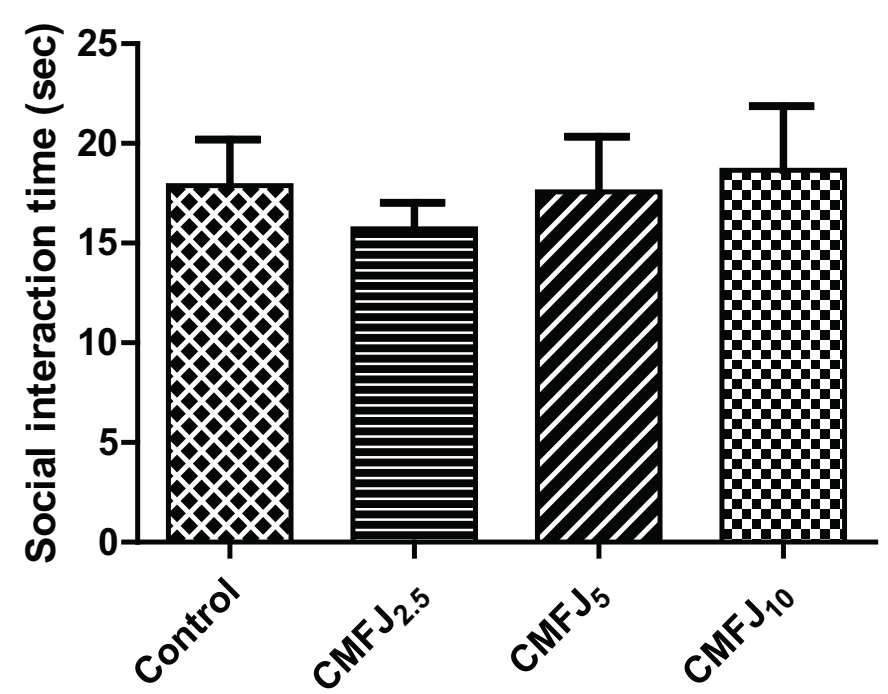

Fig. 1. Effect of CMFJ administered for 14 days on the time spent in social interaction of rats. Results are presented as mean \pm S.E.M.; $n=8$ 


\section{Forced swim test (FST)}

After 16 days of administration, all doses of CMFJ significantly decreased $(p<0.05)$ the immobility time of the treated rats in comparison with the Control group. The immobility time durations of the $\mathrm{CMFJ}_{2.5}$ group, CMFJ ${ }_{5}$ group and $\mathrm{CMFJ}_{10}$ group were respectively $61.7 \%$ of the control time, $57.0 \%$ of the control time and $59.5 \%$ of the control time (Table 1). Thus, applied for 16 days, CMFJ at all treatment doses showed a significant decrease in the immobility time in the FST (Fig. 2).

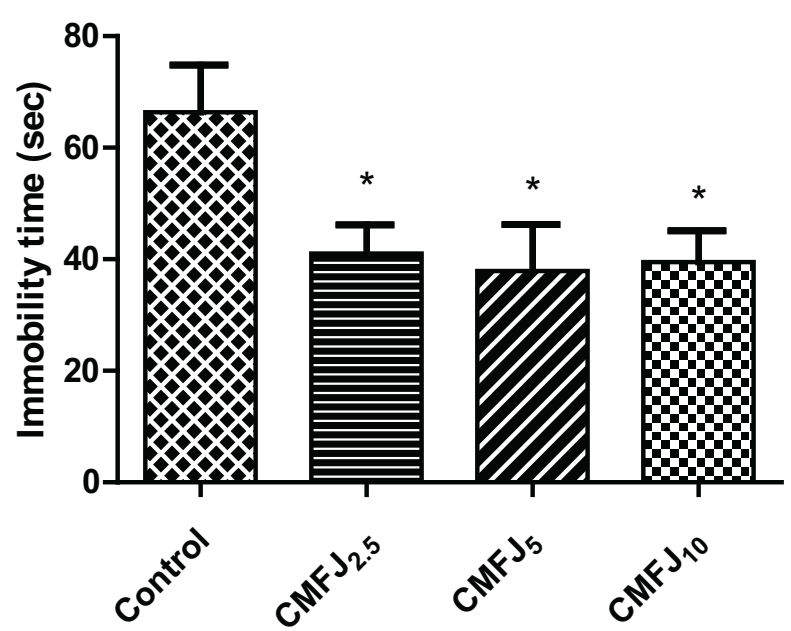

Fig. 2. Effect of CMFJ administered for 16 days on the immobility time of rats in the FST. Results are presented as mean \pm S.E.M.; $n=8,{ }^{*} p<0,05$ vs. control

\section{DISCUSSION}

Depression and anxiety are the predominant neuropsychiatric disorders. The SIT, developed by File and Hyde [19], relies on a rodent's natural tendency to avoid bright light and unfamiliar surroundings. Animals placed in a novel or brightly lit chamber exhibit decreased social interaction [23]. Anxiolytic agents increase and anxiogenic agents decrease the social contact between two unfamiliar rats in a new and unfamiliar environment [24]. In the SIT, the 14 days administration of CMFJ did not produce any significant changes in the time spent in social interaction. This could be interpreted as a lack of an anxiolytic effect.

FST, developed by Porsolt and collegues [21], is established as one of the most widely used tests for assessing antidepressant-like activity in rats, due to its reliability, specificity and ease of use [25]. The forced swim test is based on the assumption that immobility is a measure of behavioral despair [26]. The results from the present study showed that 16 days of administration of CMFJ at all doses shortened significantly the immobility time in the FST. These re- sults are consistent with the statements that some polyphenol-rich plants produce antidepressant-like effects. This may be due to their antioxidant activity and altered monoaminergic responses [27].

Antidepressants and stimulants may produce similar effects in the FST. The shortening of the immobility time might be due to either an antidepressant effect, or an increased locomotor activity. In a previous study (unpublished data), we found that CMFJ at a dose of $5 \mathrm{ml} / \mathrm{kg}$ significantly increased both the horizontal and vertical movements in the open field test, suggesting both CNS and locomotor stimulation. The dose of CMFJ $10 \mathrm{ml} / \mathrm{kg}$ did not affect significantly the locomotor activity. At the same time in the FST that dose decreased significantly the immobility time. This finding allows making the conclusion that CMFJ showed an antidepressant-like effect in the present experiment.

In the treatment of depression and anxiety, the use of naturally occurring antioxidants like polyphenols may be highly beneficial. They are the main bioactive compounds found in Chaenomeles maulei fruits. They are capable of crossing the blood-brain barrier and exert antidepressant effects [28]. Some bioactive substances from plant origin are capable of alleviating depression-like behavior by restoring the levels of serotonin, norepinephrine and dopamine in the brain [29]. Some antidepressants potentiate the responses produced by dopamine receptors stimulation, just like reward-related behaviors. Zhao et al. [30] established that Chaenomeles speciosa fruits dose-dependently inhibited the transporters for dopamine and norepinephrine reuptake, which possibly mediated antiparkinsonian-like effects. The inhibition of norepinephrine and dopamine reuptake might account for the antidepressant-like effects of CMFJ in this experiment. Polyphenols were shown to delay the initiation of and/or slow the progression of neurodegenerative disorders, including a potential to inhibit neuronal apoptosis triggered by neurotoxic species (e.g., oxidative stress and neuroinflammation) [31]. They possess a potent antioxidant capacity [32]. These findings might also be a part of the complex mechanism of action of CMFJ components.

\section{CONCLUSION}

In conclusion, CMFJ decreased the immobility time in the FST after 16 days of treatment and did not change the time spent in social interaction in the SIT. This might be interpreted as a probable antidepressant-like effect and a lack of an anxiolytic activity. 


\section{Acknowledgements}

We would like to express our gratitude to the staff of the Department of Pharmacology and Clinical Pharmacology and Therapeutics for their support and contribution to our study.

\section{Conflict of interest}

The authors have no conflict of interest to declare.

\section{REFERENCES}

1. World Health Organization. Mental and neurological disorders. Geneva: World Health Organization. [Online].; 2006 [cited 2017 October 19. Available from: http://www.who.int/ whr/2001/media_centre/en/whr01_fact_sheet1_en.pdf.

2. O'Donnell JM, Shelton RC. Drug Therapy of Depression and Anxiety Disorders [In: Brunton LL, Chabner BA, Knollmann BC. eds. Goodman \& Gilman's: The Pharmacological Basis of Therapeutics, 12e New York, NY: McGraw-Hill;].: Times by Glyph International. Available from: http://accessmedicine. mhmedical.com/content. aspx?bookid=1613\&section id $=102158640$. Accessed February 16, 2018.

3. Kessler RC, Chiu WT, Demler O. Prevalence, severity, and comorbidity of 12-month DSM-IV disorders in the National Comorbidity Survey Replicationhttp. Arch Gen Psychiat. 2005; 62(6):617-27.

4. Hindmarch I. Expanding the horizons of depression: beyond the monoamine hypothesis. Hum Psychopharmacol. 2001; 16(3):203-18.

5. Antonijevic IA. Depressive disorders-is it time to endorse different pathophysiologies? Psychoneuroendocrinol. 2006; 31(1):1-15

6. Sarris J, Kavanagh D. Kava and St. John's wort: current evidence for use in mood and anxiety disorders. J Altern Complement Med. 2009; 15(8):827-36.

7. Saki K, Bahmani M, Rafieian-Kopaei M. The effect of most important medicinal plants on two important psychiatric disorders (anxiety and depression) - a review. Asian Pac J Trop Med. 2014; 7(1):34-42.

8. $\mathrm{Du} \mathrm{H}, \mathrm{Wu} \mathrm{J}$, Li H et al. Polyphenols and triterpenes from Chaenomeles fruits: Chemical analysis and antioxidant activities assessment. Food Chem. 2013; 141(4):4260-8.

9. Елисеева ЛГ, Блинникова ОМ, Пехташева ЕЛ. Оценка потребительских свойств плодов хеномелеса Маулея. Товаровед продовольственных товаров. 2012; 6:4-7.

10. Youdim KA, Qaiser MZ, Begley DJ et al. Flavonoid permeability across an in situ model of the blood-brain barrier. Free Radic Biol Med. 2004; 36(5):592-604.

11. El Mohsen MA, Marks J, Kuhnle G et al. Absorption, tissue distribution and excretion of pelargonidin and its metabolites following oral administration to rats. Br J Nutr. 2006; 95(1): 51-8.

12. Scholey AB, French SJ, Morris PJ et al. Consumption of cocoa flavanols results in acute improvements in mood and cognitive performance during sustained mental effort. J Psychopharmacol. 2010; 24(10):1505-14.

13. Oliveira DR, Sanada PF, Saragossa Filho AC et al. Neuromodulatory property of standardized extract Ginkgo biloba L. (EGb 761) on memory: behavioral and molecular evidence. Brain Res. 2009; 1269:68-89.
14. Eftimov M, Valcheva-Kuzmanova S. Antidepressant-like effect of Aronia melanocarpa fruit juice applied subchronically to rats. Scripta Scientifica Medica. 2013; 45(6):7-11.

15. Oyama Y, Chikahisa L, Ueha T et al. Ginkgo biloba extract protects brain neurons against oxidative stress induced by hydrogen peroxide. Brain Res. 1996; 712(2):349-52.

16. Blecharz-Klin K, Piechal A, Joniec I et al. Pharmacological and biochemical effects of Ginkgo biloba extract on learning, memory consolidation and motor activity in old rats. Acta Neurobiol Exp. 2009; 69:217-31.

17. Singleton VL, Rossi JA. Colorimetry of total phenolics with phosphomolybdic phosphotungstic acid reagents. Am J Enol Viticult. 1965; 16:144-58.

18. Valcheva-Kuzmanova S, Zhelyazkova-Savova M. Anxiolyticlike effect of Aronia melanocrpa fruit juice in rats. Methods Find Exp Clin Pharmacol. 2009; 31(10):651-4.

19. File SE, Hyde JR. Can social interaction be used to measure anxiety. Br J Pharmacol. 1978; 62:19-24.

20. Irvine EE, Bagnalasta M, Marcon C et al. Nicotine self-administration and withdrawal: modulation of anxiety in the social interaction test in rats. Psychopharmacol. 2001; 153:315-20.

21. Porsolt RD, Le Pichon M, Jalfre M. Depression: a new animal model sensitive to antidepressant treatments. Nature. 1977; 266:730-2.

22. Castagne V, Moser P, Porsolt RD. Chapter 6 Behavioral Assessment of Antidepressant Activity in Rodents. Boca Raton (FL): CRC Press/Taylor \& Francis; 2009. Available from: https://www.ncbi.nlm.nih.gov/books/NBK5227/ .

23. File SE. The validation of animal tests of anxiety- pharmacological implications. Pol J pharmacol Pharm. 1984; 36: p. 505-12.

24. Rex A, Voigt J, Gustedt C et al. Anxiolytic-like profile in Wistar, but not Sprague-Dawley rats in the social interaction test. Psychopharmacol. 2004; 177:23-34.

25. Slattery DA, Cryan J. Using the rat forced swim test to assess antidepressant-like activity in rodents. Nature Protocol. 2012; 7(6):1009-14.

26. Yankelevitch-Yahav R, Franko M, Huly A et al. The Forced Swim Test as a Model of Depressive-like Behavior. J Vis Exp. 2015; 97:525-87.

27. Liu $Y$, Jia G, Gou L et al. Antidepressant-like effects of tea polyphenols on mouse model of chronic unpredictable mild stress. Pharm Biochem Behav. 2013; 104:27-32.

28. Bouayed J. Polyphenols: A Potential New Strategy for the Prevention and Treatment of Anxiety and Depression. Curr Nutr Food Sci. 2010; 6(1):13-8.

29. Jia M, Li C, Zheng Y et al. Leonurine Exerts AntidepressantLike Effects in the Chronic Mild Stress-Induced Depression Model in Mice by Inhibiting Neuroinflammation. Int $\mathrm{J}$ Neuropsychopharmacol. 2017; (https://doi.org/10.1093/ijnp/ pyx062):1-10.

30. Zhao G, Jiang Z, Zheng X. Dopamine transporter inhibitory and antiparkinsonian effect of common flowering quince extract. Pharmacol Biochem Behav. 2008; 90:363-71.

31. Mori T, Rezai-Zadeh K, Koyama N et al. Tannic acid is a natural $\beta$-secretase inhibitor that prevents cognitive impairment and mitigates Alzheimer-like pathology in transgenic mice. J Biol Chem. 2012; 287(9):6912-27.

32. Gospodinova Z, Bózsity N, Nikolova M et al. Antiproliferative Properties Against Human Breast, Cervical and Ovarian Cancer Cell Lines, and Antioxidant Capacity of Leaf Aqueous Ethanolic Extract from Cotinus coggygria Scop. Acta Medica Bulgarica. 2017; 44(2):20-5. 